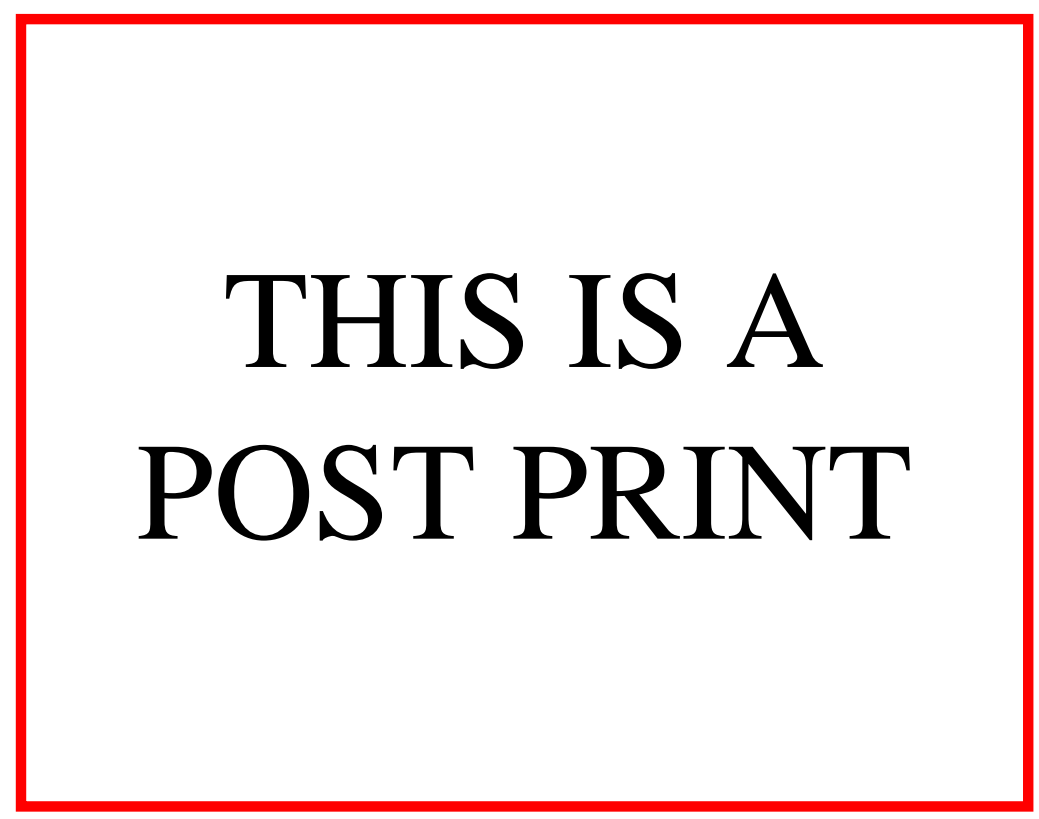




\title{
Modelling Key Parameters Characterising Land Surface in 1D Space using the SimSphere SVAT model: Findings from its use at European Ecosystems
}

\author{
Swati Suman', Matthew R. North², George P. Petropoulos ${ }^{2,3^{*}}$, Prashant K. \\ Srivastava1, Jon P. McCalmont², Daniela Silva Fuzzo4, Salim Lamine ${ }^{2,5}$, Leonidas \\ Toulios $^{2}$, Toby N. Carlson 6 \\ ${ }^{1}$ Institute of Environment and Sustainable Development, Banaras Hindu University, India \\ ${ }^{2}$ Department of Geography \& Earth Sciences, Aberystwyth University, SY23 3DB, United Kingdom \\ ${ }^{3}$ Hellenic Agricultural Organisation 'DEMETER' (NAGREF), Institute of Soil Mapping \& Classification, Larissa, \\ Greece \\ ${ }^{4}$ Paulista State University - UNESP, Renato Costa Lima Avenue, 451 - Ville de France, Brazil \\ ${ }^{5}$ Faculty of Nature \& Life Sciences \& Earth Sciences, University Akli Mohand Oulhadj of Bouira, BP 10000, \\ Bouira, Algeria \\ ${ }^{6}$ Pennsylvania State University, Department of Meteorology, University Park, PA 16802, USA \\ *Correspondence to: George P. Petropoulos (petropoulos.george@gmail.com), Tel: +44 -0-1970-621861
}

\begin{abstract}
The present study investigates the ability of SimSphere, a Soil Vegetation Atmosphere Transfer (SVAT) model, to predict key parameters in characterising land Surface interactions. In particular, the model's performance in predicting Net Radiation ( $\left.\mathrm{R}_{\mathrm{net}}\right)$, Latent Heat (LE), and Sensible Heat $(\mathrm{H})$ was examined. For this purpose, concurrent in-situ measurements of the corresponding parameters for a total of 70 days of the year 2011 from 7 CarboEurope network sites were acquired, incorporating a variety of environmental biomes and climatic conditions in the model evaluation. In overall, SimSphere was largely able to accurately predict the variables against which it was evaluated for most of the experimental sites. Statistical analysis showed highest agreement of $\mathrm{H}$ fluxes to the measured in-situ values for all ecosystems, with an average RMSD of $55.36 \mathrm{Wm}^{-2}$. Predicted LE fluxes and $\mathrm{R}_{\text {net }}$ also agreed well with the corresponding in-situ data with RSMDs of $62.75 \mathrm{Wm}^{-2}$ and $64.65 \mathrm{Wm}^{-2}$ respectively. Our findings contribute towards a better understanding of the model structure, functioning and its correspondence to the real world system. Also further establish its capability as a useful teaching and research tool in modelling Earth's land surface interactions. This is important given its increasing use, including its synergies with Earth Observation data.
\end{abstract}

\section{KEYWORDS: SimSphere, Validation, SVAT, CarboEurope, Earth Observation}




\section{INTRODUCTION}

Accurate monitoring of water and vegetation stress is now of prominent global concern and it is regarded as a high priority issue (Petropoulos et al., 2016). Much emphasis is placed on the accurate monitoring of the effects of climate change on water and vegetation, particularly for communities located in the Mediterranean region having water scarce ecosystems (Amri et al., 2014). Thus, studies on the partitioning of incoming energy into heat and water fluxes is crucial in understanding the mechanism of climate change. The terrestrial boundary layer and its vegetation play a critical role in regulating the partitioning of incoming energy (into Latent (LE), Sensible (H) and Ground (G) heat fluxes), having an effect in photosynthesis and the energy and water vapour cycles (Prentice et al., 2014).

Research on improving our understanding of the representation of land atmosphere interactions has led to the development and exploration of a wide variety of different modelling schemes. A number of Land Surface Models (LSMs) for assessing the contribution of different variables associated with land surface interaction at various degrees of complexities have been developed since the 1970's. Since then, LSMs have evolved from simple bucket models without vegetation consideration (e.g. Manabe, 1969) into contemporary versions with credibly detailed representations of the exchanges of energy, water and $\mathrm{CO}_{2}$ in the soil-vegetation-atmosphere continuum. Among various forms of LSMs, Soil Vegetation Atmosphere Transfer (SVAT) models are increasingly gaining recognition in land surface processes and Earth's system component studies (Ireland et al., 2015). SVATs are mathematical representations of vertical 'views' of the physical mechanisms controlling energy and mass transfers in the soil -vegetation-atmosphere continuum. Those models are able to provide deterministic estimates of the time course of soil and vegetation state variables at time-steps compatible with the dynamics of atmospheric processes. Fine temporal resolution (often $<1$ hour) of SVAT models allows simulations to be in satisfactory agreement with the timescale of the physical process being simulated.

Developed by Carlson and Boland (1978), SimSphere is a SVAT model that simulates and enhances our understanding of boundary layer processes and is being extensively used as a research, educational and training tool within several universities worldwide. SimSphere these days has gained a lot of popularity as an extensive tool being synergistically used with Earth Observation (EO) data due to its ability to provide spatio-temporal estimates of evapotranspiration (ET) rates and surface soil moisture. Most of these investigations have been based around the implementation of a data assimilation technique termed the "triangle" (Petropoulos \& Carlson, 2011). Variants of this technique are currently investigated by different Space Agencies for developing related operational products (Chauhan et al., 2003; Piles et al., 2011; Piles et al., 2016). A series of SA experiments have already been conducted on SimSphere (Petropoulos et al., 2009b; Petropoulos et al., 2013a-c; 2014). Those studies provided for the first time independent evidence to enhance our understanding of the model's behaviour, coherence and correspondence to that it has been built to simulate (Petropoulos et al., 2009a; Petropoulos et al., 2013a-c; 2014). However, SimSphere validation has previously only been performed over a very small range of land use/cover types (e.g. Todhunter and Terjung, 1987; Ross and Oke, 1988; Petropoulos et al., 2015). Given its current global expansion, such a comprehensive validation of it is both timely and of fundamental importance to further establishes the model's structure, coherence and representativeness in terms of its ability to realistically represent Earth's land surface interactions.

In light of the above, this study's objective has been to investigate the ability and applicability of SimSphere to simulate a series of significant variables characterising land surface interactions 
and specifically: Net Radiation $\left(\mathrm{R}_{\text {net }}\right)$, Latent Heat (LE) and Sensible Heat $(\mathrm{H})$. For this, purpose, in-situ measurements a total of 70 days selected from 7 model European ecosystems sites representative of different conditions the CarboEurope monitoring network in Europe have been used to validate the model's output.

\section{MODEL FORMULATION}

SimSphere simulates the land-atmosphere exchanges taking place in a vertical column that extends from the root zone below the soil surface up to a level well above the surface canopy, the top of the surface mixing layer. SimSphere was considerably modified to its current state by Gillies et al. (1997) and later by Petropoulos et al. (2013d) and Anagnostopoulos et al., (in press). It is currently maintained and freely distributed by Aberystwyth University, United Kingdom (http://www.aber.ac.uk/simsphere). A detailed description of its architecture can be found in Gillies (1993) and an overview on its use can be found in Petropoulos et al., (2009 b).

Briefly, SimSphere is a 1-dimensional two-source SVAT model with a plant component (input parameters shown in Table 1). The model structure is an integrated form of 3 major components namely the physical, vertical and horizontal layers. The physical component determines the microclimate in the model and primarily takes account of the available radiant energy radiant energy reaching the surface in clear sky condition or the plant canopy. The component is calculated as a function of sun and Earth geometry, atmospheric transmission factors for scattering and absorption, the atmospheric and surface emissivity's and surface (including soil and plant) albedos. The vertical structure components (Fig. 1, right), effectively corresponds to the components of the Planetary Boundary Layer (PBL) that are divided into three layers - a surface mixing layer, a surface of constant flux layer and a surface vegetation or bare soil layer. Vegetation and soil fluxes mix at the top of the vegetation canopy. Their relative weights depend on the fractional vegetation cover (FVC), specified as an input to the model. The soil hydraulic parameters are prescribed from the Clapp and Hornberger (1978) classification. The soil surface turbulent fluxes are determined following the Monin and Obukhov (1954) similarity theory which takes into account atmospheric stability. The Atmospheric Boundary Layer (ABL) conditions are provided by a one dimensional ABL model.

SimSphere simulates the processes and the interaction between soil, plant and atmosphere layers over a 24-hour cycle. The cycle runs at a chosen time step, starting generally from the early morning (at 06: 00 am local time) to monitor the continuously evolving interaction between the input layers. A number of input parameters are required to parameterise the model, categorised into 7 defined groups (Table 1) and the model provides predictions as a function of time for a total of more than 30 variables (Table 1).

\section{Figure 1: (Left) The three facets of SimSphere Architecture, (Right) different layers represented within SimSphere's vertical domain}

\section{MATERIALS AND METHODS}

Figure 2 provides details of the methodology followed to parameterise and validate SimSphere targeted outputs, whereas the major steps involved in this process are outlined below.

\subsection{In-situ Datasets Collection}


This study evaluates the ability of SimSphere Soil Vegetation Atmosphere Transfer (SVAT) model in providing diurnal estimates of key variables characterising water and energy balance at 7 CarboEurope sites, part of a larger observational network, FLUXNET (Baldocchi et al., 2001),. The sites used in our study were selected as representative of different ecosystem types (see Table 2). In-situ data for selected sites were acquired from the European Fluxes database Cluster (http://gaia.agraria.unitus.it/) for the year 2011. In particular Level 2 data were obtained across all selected sites for consistency. This product includes the originally acquired in-situ measurements from which only the removal of erroneous data caused by obvious instrumentation error were undertaken. In addition, atmospheric profile (i.e. radiosonde) data as atmospheric temperature profile, dew point temperature, wind direction, wind speed and atmospheric pressure were obtained for each site/day from the University of Wyoming (http://weather.uwyo.edu/upperair/sounding.html).

Figure 2: Overall methodology of SimSphere validation followed in this study

Initially, for each site, cloudy days were identified and were subsequently excluded from further analysis. Identification of cloudy days was carried out using diurnal incoming global solar radiation (Rg) observations. As cloud-free days were flagged as those having smoothly symmetrical Rg curves and as cloudy those having an asymmetrical one (Carlson et al., 1991). Subsequently, energy balance closure (EBC) for those clouds free days only was evaluated. EBC is believed to be the most relevant energy measurement tool as its magnitude depends on more accurate entities such as Latent Heat (LE) and Sensible Heat $(\mathrm{H})$ and not on other scaler fluxes such as $\mathrm{CO}_{2}$ (Wilson et al., 2002; Foken et al., 2006). EBC was evaluated principally by calculating the linear regression coefficients (slope and intercept) as well as the coefficient of determination $\left(R^{2}\right)$ from the ordinary least squares (OLS) relationship between the half-hourly estimates of the dependent flux variables $(\mathrm{LE}+\mathrm{H})$ and the independently derived available energy $\left(\mathrm{R}_{n e t}-\mathrm{G}-\mathrm{S}\right)$. In addition, the Energy Balance Ratio (EBR) was also computed by cumulatively summing $\mathrm{R}_{\text {net }}-\mathrm{G}-\mathrm{S}$ and $\mathrm{LE}+\mathrm{H}$ from the 30-min mean average surface energy flux components, and then rationing each of the cumulative sums as follows (Liu et al., 2006):

$$
E B R=\frac{\sum(L E+H)}{\sum(\text { Rnet }-G-S)}
$$

where LE is the Latent Heat, $H$ is the Sensible Heat, $R_{\text {net }}$ is the net radiation, $G$ is the heat flux into the soil, and $\mathrm{S}$ is the rate of change of heat storage (air and biomass). This index ranges generally from zero to one, with values closer to one highlighting a satisfactory diurnal energy closure, indicating a good quality of in-situ measurements.

All days with low EBC (i.e. EBR $<0.750$, slope $<0.85, \mathrm{R}^{2}<0.930$ ) were excluded from further analysis. Further constraints were applied to calibrate the selected data quality with the in-situ data quality which was performed over several steps. Secondly, atmospherically stable conditions, such as low wind speeds and small available energy, were selected for the evaluation simulation days (Maayar et al., 2001). Such conditions were identified during evaluation of the insitu dataset, where direct measurements of wind speed and energy flux amplitude and diurnal trend were used as indicators of atmospherically stable conditions. In total a set of 70 nonconsecutive days from the 7 CarboEurope sites were identified as being suitable to include in the model verification. 


\subsection{SimSphere Parameterisation \& Implementation}

172 SimSphere parameterisation was carried out at the measurement scale of the flux tower observations, i.e. the area of the possible measurement fetch around which the tower is built and the footprint of the turbulent flux measurements, representing an area of $\sim 1 \mathrm{~km}^{2}$ for the test sites as they are relatively homogeneous. On this basis, SimSphere was parameterised to the daily conditions existent at the flux tower for each of the selected days.

177 For each day the model was parameterised to the daily existing conditions at the flux tower up to a height of 54,000ft. Initial conditions for air temperature, dew point temperature, atmospheric pressure, wind speed and direction were used within the 'Wind Sounding' and 'Water Vapour Sounding' components of the model. These details were data were acquired from the publically available University of Wyoming database, and were collected at 6:00am GMT to correspond to the model's initialisation. Ancillary information on vegetation and soil parameters (e.g. Leaf area index - LAI, FVC, vegetation height, soil type etc.) was also used directly within the model's initialisation. Such information was acquired in most cases directly from communication with the principal investigators of each respective site, though in some cases it had to be acquired from standard literature sources (e.g. Mascart et al., 1991; Carlson et al., 1991). The soil type parameters were obtained using the soil texture data provided at each CarboEurope test site. Similarly, this was also the case for the topographical information that was required in model initialisation. Upon model initialisation, the model was executed for each site/day and the 30' average value of each of the evaluated parameters per site for the period 0530-2330 hours was subsequently exported in SPSS for comparisons against the corresponding in-situ data.

\subsection{Validation}

To analyse the correlation of the model simulated values to the observed, a series of statistical approaches based on the results of many previous similar studies (e.g. Giertz et al., 2006; Marshall et al., 2013). Those included were root mean square difference [RMSD], the linear regression fit model coefficient determination [ $\left.\mathrm{R}^{2}\right]$, the Bias or Mean Bias Error [MBE], the Scatter or mean standard deviation [MSD], the mean absolute error [MAE] and the NASH index, tabulated in Table 3. MSD was employed to express the model precision and ultimately for the correction of non- systematic error. All statistical matrices were computed from the comparative analysis of the two datasets for each day of comparison at 30' intervals. The same set of statistical metrics was performed on the dataset for each of the CarboEurope sites for each of the selected days.

\section{RESULTS}

\subsection{Net Radiation $\left(R_{\text {net }}\right)$ flux}

The results of the analysis between SimSphere predicted and in-situ Net radiation measurement are summarised in Table 4. Furthermore, Figure 3a illustrates the agreement between the insitu and the predicted $\mathrm{R}_{\mathrm{net}}$ for all days of comparisons from all experimental sites. For most of the compared days diurnal variation of the simulated $R_{\text {net }}$ in general was found in close correspondence with the observed $\mathrm{R}_{\text {net }}$ both in shape and magnitude (although results are not shown here for brevity).

In overall, $\mathrm{R}_{\text {net }}$ simulated by SimSphere was found to be reasonably accurate with an average RMSD of $64.65 \mathrm{Wm}^{-2}$ and a correlation coefficient of 0.96. A minor underestimation of the in-situ 
data was evident for all sites and days combined (MBE $\left.=-2.07 \mathrm{Wm}^{-2}\right)$, though overall $\mathrm{R}_{\text {net }}$ showed a significant range of agreement, with RMSD ranging from 24.38 to $98.26 \mathrm{Wm}^{-2}$ between the validation days. Interestingly, a noticeable trend between extended observation time period and simulation accuracy was observed within a number of test sites. Also, notably, there were increased periods within a number of test sites where simulation accuracy was found increasing depending on the period in which the simulation days were located. Such trends were observed for the IT_Ro3 cropland site, where error ranges decreased for the period between late April (21/04/2011) and late August (28/08/2011), before increasing in early September (09/09/2011). However, the periods of increased accuracy varied on a per site basis and were only prevalent within the olive plantation (ES_Lju), grassland (IT_Mbo), cropland (IT_Ro3) and deciduous broadleaf forest (IT_Col) sites. Daily $\mathrm{R}^{2}$ values exhibited less variance with generally more comparable ranges $(0.909-0.998)$ between all the study days, suggesting a satisfactory agreement between both datasets, also illustrated by the distribution of the points around the 1:1 line in Figure 3a. This was also reflected within the NASH index values reported (0.897 - 0.999).

When averaged per site, RMSD showed significantly less variance, exhibiting a range from $55.86 \mathrm{Wm}^{2}$ (IT_Lav) to $68.49 \mathrm{Wm}^{-2}$ (FR_Pue). This trend was also reflected by lower variance in correlation coefficients $\left(R^{2}=0.936-0.970\right)$ and NASH index values $(0.943-0.981)$ for the per site averages. The evergreen needle-leaf forest site, IT_Lav, consistently demonstrated the highest model performance in simulating $\mathrm{R}_{\text {net }}$ with an RMSD value of $55.86 \mathrm{Wm}^{-2}$, that being 8.79 $\mathrm{Wm}^{-2}$ lower than the overall average. MBE between sites showed significant variability, ranging from a moderate underestimation of the in-situ measurements over the evergreen broadleaf forest site $\left(-15.99 \mathrm{Wm}^{-2}\right)$, to a moderate overestimation within the shrubland site $\left(15.02 \mathrm{Wm}^{-2}\right)$. All in all, SimSphere was able to reproduce $\mathrm{R}_{\text {net }}$ reasonably well in terms of both amplitude and trend. Indeed, this is reflected in the low MSD values of all sites (55.01-68.03 $\mathrm{Wm}^{-2}$ ), particularly so at sites such as IT_Lav $\left(55.01 \mathrm{Wm}^{-2}\right)$ and ES_Agu $\left(60.92 \mathrm{Wm}^{-2}\right)$.

Figure 3: Comparisons of predicted and observed a) $\mathrm{R}_{\text {net }}$ fluxes $\left(\mathrm{Wm}^{-2}\right)$, b) LE fluxes $\left.\left(\mathrm{Wm}^{-2}\right), \mathrm{c}\right) \mathrm{H}$ fluxes $\left(\mathrm{Wm}^{-2}\right)$, and d) Tair at $50 \mathrm{~m}\left({ }^{\circ} \mathrm{C}\right)$

\subsection{Latent Heat (LE) flux}

SimSphere simulated LE flux and the CarboEurope LE measurement for all combined days exhibited an overall average RMSD error of $62.75 \mathrm{Wm}^{-2}$ and a correlation coefficient value of 0.542 respectively (Table 5). Although RMSD for the LE output showed a better agreement in comparison to the $\mathrm{R}_{\text {net }}$ output (section 4.1), $\mathrm{R}^{2}$ was significantly lower (a decrease of 0.408 ). As can be seen from Figure $\mathbf{3 b}$, the distribution of points shows an increased dispersion from the 1:1 line in comparison to the $\mathrm{R}_{\text {net }}$ output. There was also an apparent overestimation of the in-situ measurements by the model for the LE flux $\left(\mathrm{MBE}=15.78 \mathrm{Wm}^{-2}\right) . \mathrm{R}^{2}$ values varied significantly between all simulation days from $0.020-0.961$, suggesting notable discrepancies between the predictions and observations. Additionally, daily RMSD values also varied significantly, reflecting the trends observed in the $\mathrm{R}^{2}$ statistics. RMSD varied from $22.08 \mathrm{Wm}^{-2}$ to $86.45 \mathrm{Wm}^{-2}$ between all days of simulation. When analysed on a site by site basis, average RMSD exhibited comparable ranges to those reported for the individual simulation days, with RMSD varying from $37.25 \mathrm{Wm}^{-2}$ (ES_Agu - Shrubland) to $75.36 \mathrm{Wm}^{-2}$ (IT_Col, deciduous broadleaf forest). On a per site basis, ES_Agu shrubland site consistently demonstrated above average correlation to the in-situ measurements with the lowest RMSD and MAE values of all sites, $37.25 \mathrm{Wm}^{-2}$ and $25.58 \mathrm{Wm}^{-2}$ respectively. Lowest agreement between the LE fluxes predicted from SimSphere and those from 
the in-situ measurements was in the IT_Col deciduous broadleaf forest site (RMSD $=75.36 \mathrm{Wm}^{-2}$, MAE $=55.86 \mathrm{Wm}^{-2}$ ) and IT_Mbo grasslands site $\left(\right.$ RMSD $=74.66 \mathrm{Wm}^{-2}, \mathrm{MAE}=52.87 \mathrm{Wm}^{-2}$ ) respectively. On the whole, SimSphere was consistent in terms of its ability to reproduce in-situ LE fluxes, with low MSD values across most sites. Yet, the IT_Mbo (grassland) and IT_Ro3 (cropland) sites exhibited the largest MSD of $74.58 \mathrm{Wm}^{-2}$ and $68.48 \mathrm{Wm}^{-2}$ respectively, an increase of $15.64 \mathrm{Wm}^{-2}$ and $9.54 \mathrm{Wm}^{-2}$ on the overall average suggesting a weaker systematic replication of LE fluxes over those sites (Table 5). There was a systematic overestimation of LE for the majority of sites. Exceptions were only the IT_Mbo and IT_Ro3 sites, exhibiting a small average underestimation (MBE) of $-3.45 \mathrm{Wm}^{-2}$ and $-0.87 \mathrm{Wm}^{-2}$ respectively. Interestingly, both broad-leaf forest sites, IT_Col (deciduous broad-leaf forest) and FR_Pue (evergreen broad-leaf forest), showed the highest overestimation of LE fluxes with moderately high MBE values of $33.67 \mathrm{Wm}^{2}$ and $37.56 \mathrm{Wm}^{-2}$ respectively.

\subsection{Sensible Heat (H) flux}

Concerning the $\mathrm{H}$ fluxes, results showed high performance of the model in simulating values for $\mathrm{H}$ fluxes with an average RMSD of RMSD of $55.36 \mathrm{Wm}^{-2}$ and an $\mathrm{R}^{2}$ value of 0.83 ( Figure 3c , Table 6). A significant improvement in the accuracy of the simulation of the model output in comparison to both the $\mathrm{R}_{\text {net }}$ and $\mathrm{LE}$ was evident. $\mathrm{H}$ flux results exhibited a decrease in overall RMSD of $9.29 \mathrm{Wm}^{-2}$ and $7.39 \mathrm{Wm}^{-2}$ respectively. Similar trends were also evident in both the MBE $\left(-0.08 \mathrm{Wm}^{-2}\right)$ and MSD (53.56 $\left.\mathrm{Wm}^{-2}\right)$ results for this output, where model performance was better in comparison to both the $\mathrm{R}_{\text {net }}$ and $\mathrm{LE}$ outputs. Although with regards to $\mathrm{R}^{2}$, the $\mathrm{H}$ flux output exhibited a minor decrease in correlation (0.83) compared to the $\mathrm{R}_{\text {net }}$ output When examining the $\mathrm{R}^{2}$ values for the individual simulation days, there was a significant variation in both correlation coefficients $\left(\mathrm{R}^{2}=0.607-0.982\right)$ and $\mathrm{RMSD}\left(\mathrm{RMSD}=20.03-91.07 \mathrm{Wm}^{-2}\right)$. RMSD ranged from $35.50 \mathrm{Wm}^{-2}$ (ES_Agu) to $71.93 \mathrm{Wm}^{-2}$ (IT_Ro3) on a site by site basis. Similarly to LE flux, the ES_Agu site reported the highest simulation accuracy $\left(\mathrm{RMSD}=35.50 \mathrm{Wm}^{-2}, \mathrm{R}^{2}=0.944, \mathrm{MBE}=\right.$ $7.01 \mathrm{Wm}^{-2}, \mathrm{MSD}=34.80 \mathrm{Wm}^{-2}$ ). On the contrary, the cropland site IT_Ro3 consistently reported a less satisfactory agreement between model prediction and in-situ data for $\mathrm{H}$ flux. Generally, SimSphere was often unable to represent the peak of $\mathrm{H}$ flux across all sites diurnally; this is shown by a scatter of peak values as reported in Figure 3c. However, the model did neither consistently overestimate nor underestimate $H$ flux, but produced a range of bias values, with an average error of $-0.08 \mathrm{Wm}^{-2}$. Both the FR_Pue and ES_Lju sites showed a predominant underestimation of $\mathrm{H}$ flux at $-16.29 \mathrm{Wm}^{-2}$ and $-17.17 \mathrm{Wm}^{-2}$ respectively. Yet, for the IT_Mbo site, a moderate overestimation of $16.41 \mathrm{Wm}^{-2}$ was reported, suggesting land cover type may be related to simulation accuracy.

\section{DISCUSSION}

This study presents an evaluation of the SimSphere SVAT model's ability in simulating key variables characterising Earth's land/surface interaction across a range of European ecosystems. The model was parameterised for seven sites where a total of 70 days (10 days per site) from the year 2011 were selected to validate the model's ability to predict Net Radiation $\left(R_{n e t}\right)$, Latent Heat (LE) and Sensible Heat (H). The agreement between the two datasets was evaluated based on a series of computed statistical metrics using, as reference, in-situ data acquired from selected sites belonging to the CarboEurope monitoring network. 
In overall, results showed highest agreement of $\mathrm{H}$ fluxes to the measured in-situ values for all ecosystems, with an average RMSD of $55.36 \mathrm{Wm}^{-2}$. Predicted LE fluxes and $\mathrm{R}_{\text {net }}$ also agreed well with the corresponding in-situ data with RSMDs of $62.75 \mathrm{Wm}^{-2}$ and $64.65 \mathrm{Wm}^{-2}$ respectively. Very high values of the Nash-Sutcliffe efficiency index were also reported for all of the model outputs evaluated ranging from 0.720 to 0.998 , suggesting a very good model representation of the observations.

Those findings are largely in accordance to previous analogous verification studies reported on the model. For example, Ross and Oke (1988) performed a validation of a previous version of SimSphere over an urban environment of Vancouver, Canada and reported an acceptable agreement for $\mathrm{H}$ fluxes (average RMSE $=56 \mathrm{Wm}^{-2}$ ); however significant average error ranges for LE fluxes (RMSE $=107 \mathrm{Wm}^{-2}$ ) were also reported in their study. Also, Ross \& Oke (1988) noted that noted that peak values of air temperature diurnal variability should be observed between 1030 - 1430 LST, this is in close correlation to this present study, further appraising SimSphere's representation of $\mathrm{T}_{\text {air }}$ at $50 \mathrm{~m}$. Todhunter and Terjung (1987) further described in detail how earlier versions of SimSphere dissipated too much of Rnet as LE flux and too little to be lost to H; the latter correlates well to the Ross and Oke's findings (1988) but also the findings reported within; where average bias values indicate general net overestimations of LE flux in the order of $15.78 \mathrm{Wm}^{-2}$, compared to the slight average underestimation of $\mathrm{H}$ flux at $-0.08 \mathrm{Wm}^{-2}$. Yet when compared with $\mathrm{R}_{n \text { et, }}$, the simulated values of $\mathrm{LE}$ and $\mathrm{H}$ fluxes demonstrated improved model performance confirmed by the low average RMSD and high overall R². Petropoulos et al. (2015) in a verification of the model outputs at ecosystems located in the USA and Australia a good agreement between the model predictions and the in-situ measurements (particularly so for the LE, $\mathrm{H}$, with RMSDs of $39.47 \mathrm{Wm}^{-2}$ and $55.06 \mathrm{Wm}^{-2}$ respectively).

Among all selected experiment sites, the shrubland located at ES_Agu consistently showed remarkably low average RMSD in all model outputs assessed, particularly so for LE and H fluxes. This is likely to be related to the site's characteristics, located within a water limited environment, where transpiration effects are much lower in amplitude and thus more predictable, especially given the site's relative homogeneity (Maayar et al., 2001). Akkermans et al. (2012) stated that underestimations of LE can largely be attributed to overestimations of $\mathrm{H}$. Such effects were seen most prominently in our validation site ES_LJU, where a general underestimation of LE (MBE $=-17.17 \mathrm{Wm}^{-2}$ ) partly contributed to the significant overestimation of $\mathrm{H}$ flux $\left(\mathrm{MBE}=21.09 \mathrm{Wm}^{-2}\right.$ ). Also, for example Marshall et al. (2013) have suggested that ecosystems which exhibit increased stand complexity and heterogeneity, such as forested environments (particularly those with understory vegetation), can have a profound effect on the overall exchange of mass and energy.

In the overall evaluation of the results concerning the model agreement to the in-situ, instrumentation uncertainty in the measured variables themselves should also be partially taken into account when attempting to explain the disagreement between the simulated and observed variables (Bellocchi et al., 2010; Oncley et al., 2007; Verbeeck et al., 2009). Generally, $\mathrm{R}_{\text {net }}$ measurement accuracy error is in the order of $10 \%$, although, an additional $10 \%$ instrumentation uncertainty should be added due to limited view angle/measuring volume (especially in the case of rugged terrains) (Baldocchi et al., 2001). Typical uncertainty in the LE and $\mathrm{H}$ estimation using the eddy covariance generally varies between $10 \%$ to $20 \%$ but can be much higher during periods of low flux magnitude and/or limited turbulent mixing such as at night (Petropoulos et al. 2013d). For example, Hollinger and Richardson (2005) showed that uncertainty in flux measurements is inversely proportional to magnitude, the smaller the flux the greater the relative uncertainty. Also, it should be noted that for some days included in our 
comparisons, a characteristic of the acquired in-situ data for those days was the presence of many spikes (indicative of very high or very low values). Possible reasons for those spikes could be instrumental errors, horizontal advection of $\mathrm{H}_{2} \mathrm{O}$ and $\mathrm{CO}_{2}$, footprint changes as well as a nonstationarity of turbulent regime within the atmospheric surface layer (Papale et al., 2006). For those days, comparisons resulted in a somewhat lower accuracy of model predictions as such conditions cannot be replicated by the model which assumes homogeneity of vegetation canopy and ignores horizontal advection.

On the whole, despite the occasionally inferior performance of SimSphere in simulating the examined model outputs for some days/sites, model predictions were found significant in terms of the representation of the physical and dynamic processes involved in the interactions of the complex nature of the soil-land-atmosphere system. Moreover, it is important to recognise that uncertainty is inevitable in any model, which as a model will never be as complex as the reality it portrays. In this way, SimSphere fulfils its objective as a tool as it identifies the expected trends and patterns of change, if not always the magnitudes.

\section{CONCLUDING REMARKS}

In this study, key findings from a large scale validation of the SimSphere land biosphere model in numerous European environments were reported. In total, the model's ability to predict Net Radiation $\left(\mathrm{R}_{\text {net }}\right)$, Latent Heat (LE) and Sensible Heat $(\mathrm{H})$ at 7 ecosystems and for 70 cloud free days in 2011 was examined. A systematic statistical analysis was employed to assess the agreement between model predictions and corresponding in-situ measurements. To our knowledge, this is the first study reporting results on the validation of SimSphere's ability in accurately simulating key variables characterising land surface processes, particularly so in European ecosystems.

In overall, SimSphere was able to predict largely accurately the evaluated parameters for most of the experimental sites. The evaluation and analysis of a model performance allowed for an increased understanding of the model's representation. This study results provide further independent evidence that SimSphere has a high capability of simulating variables associated with the Earth's energy and water balance. As noted by Verbeeck et al. (2009), discrepancies found in any validation study should be regarded as a positive step when evaluating model performance. Such studies can also advance our understanding on the amount of complexity required for adequate representation of land surface processes and interactions between different components of our Earth system. Further efforts should be directed towards validating SimSphere at other ecosystems globally as this will allow assessing its applicability as a universally applied SVAT model. Moreover, as use of the model is currently being explored synergistically with EO data, including its possible expansion to a 2D model, it would be of utmost interest to evaluate the overriding effects of SimSphere predictions to the overall prediction error derived from such synergistic methods.

\section{Acknowledgments}

Dr. Petropoulos acknowledges the financial support provided by the European Commission under the Marie Curie Individual Fellowship project "ENViSIoN-EO". Authors would also like to thank Ms Daisy Rendall and Ms Thalia Tataris for their positive contributions to data processing and model implementation. We thank as well the PI's of the CarboEurope network for sharing the acquired data of their experimental sites. 
Akkermans, T., Lauwaet, D., Demuzere, M., Vogel, G., Nouvellon, Y., Ardö, J. and Van Lipzig, N.: Validation and comparison of two soil-vegetation-atmosphere transfer models for tropical Africa, J. Geophys. Res-Biogeo. (2005-2012), 117, 2012.

Amri, R., Zribi, M., Lili-Chabaane, Z., Szczypta, C., Calvet, J. C. and Boulet, G.: FAO-56 Dual Model Combined with Multi-Sensor Remote Sensing for Regional Evapotranspiration Estimations, Remote Sens., 6, 5387-5406, 2014.

Anagnostopoulos, V. \& Petropoulos, G.P.: A Modernized Version of a 1D Soil Vegetation Atmosphere Transfer model for use in Land Surface Interactions Studies. Environmental Modelling \& Software, 2017 [in press]

Baldocchi, D., Falge, E., Gu, L., Olson, R., Hollinger, D., Running, S. and Wofsy, S.: FLUXNET: A new tool to study the temporal and spatial variability of ecosystem-scale carbon dioxide, water vapour, and energy flux densities, B. Am. Meteorol. Soc., 82, 2415-2434, 2001.

Bellocchi, G., Rivington, M., Donatelli, M. and Matthews, K.: Validation of biophysical models: issues and methodologies. A review, Agron. Sustain. Dev., 30, 109-13. 2010.

Carlson, T. N. and Boland, F. E.: Analysis of Urban-Rural Canopy Using a Surface Heat Flux/Temperature Model, J. Appl. Meteorol., 17, 998-1014, 1978.

Carlson, T. N., Belles, J. E. and Gillies, R. R.: Transient water stress in a vegetation canopy: simulations and measurements, Remote Sens. Environ., 35, 175-186, 1991.

Chauhan, N.S., Miller, S. and Ardanuy, P.: Spaceborne soil moisture estimation at high resolution: a microwave-optical/IR synergistic approach, Int. J. Remote Sens., 22, 45994646, 2003.

Clapp, R. B. and Hornberger, G. M.: Empirical equations for some soil hydraulic-properties, Water Resour. Res., 14, 601-604, 1978.

Foken, T., Wimmer, F., Mauder, M.., Thomas, C. and Liebethal C.: Some intercepts of energy balance closure, Atmos. Chem. Phys., 6, 4395-4402, 2006.

Giertz, S., Diekkrüger, B. and Steup, G.: Physically-based modelling of hydrological processes in a tropical headwater catchment (West Africa)-process representation and multi-criteria validation, Hydrol. Earth Syst. Sc., 10, 829-847, 2006.

Gillies, R. R., Carlson, T. N., Cui, J., Kustas, W. P., and Humes K.S.: Verification of the "triangle" method for obtaining surface soil water content and energy fluxes from remote measurements of the Normalized Difference Vegetation Index NDVI and surface radiant temperature, Int. J. Remote Sens., 18, 3145-3166, 1997.

Gillies, R. R.: A physically-based land sue classification scheme using remote solar and thermal infrared measurements suitable for describing urbanisation. PhD Thesis, University of Newcastle, UK, 121pp, 1993.

Hollinger, D. \& Richardson, A.: Uncertainty in eddy covariance measurements and its application to physiological models, Tree Physiol, 25, 873-885, 2005.

Ireland, G., Volpi, M. \& G.P., Petropoulos (2014): Semi-automated flooded area cartography from EO single image analysis and machine learning: a case study from a Mediterranean river flood. Remote Sensing MDPI, 7, 3372-3399.

Liu, Y., Hiyama, T. and Yamaguchi Y.: Scaling of land surface temperature using satellite data: A case examination on ASTER and MODIS products over a heterogeneous terrain area, Rem. Sens. Envir., 105, 115-128, 2006.

Maayar, M., Price, D. T., Delire, C., Foley, J. A., Black, T. A. and Bessemoulin, P.: Validation of the Integrated Biosphere Simulator over Canadian deciduous and coniferous boreal forest stands, J. Geophys. Res-Atmos. (1984-2012), 106, 14339-14355, 2001. 
Manabe, S.: Climate and the ocean circulation 1. The atmospheric circulation and the hydrology of the earth's surface, Mon. Weather. Rev., 97, 739-774, 1969.

Marshall, M., Tu, K., Funk, C., Michaelsen, J., Williams, P., Williams, C. and Kutsch, W.: Improving operational land surface model canopy evapotranspiration in Africa using a direct remote sensing approach, Hydrol. Earth Syst. Sc., 17, 1079-1091, 2013.

Mascart P, Taconet O, Pinty J.P. and Mehrez M., B.: Canopy resistance formulation and its effect in mesoscale models: a HAPEX perspective, Agric. For. Meteorol., 54, 319-351, 1991.

Monin, A. S. and Obukhov, A.: Basic laws of turbulent mixing in the surface layer of the atmosphere, Contrib. Geophys. Inst. Acad. Sci. USSR, 151, 163-187, 1954.

Oncley, S.P., Foken, T., Vogt, R., Kohsiek, W., DeBruin, H. A. R, Berhofer, C., Christen, A., Van Gorsel, E., Grantz, D., Feigenwinter, C., Lehner, I., Liebethal, C., Liu, H., Mauder, M., Pitacco, A., Ribeiro, L. and Weidinger, T.: The Energy Balance Experiment EBEX-2000. Part I: overview and energy balance. Bound-Lay. Meteoro., 123, 1-28, 2007.

Papale, Dario; Reichstein, M; Aubinet, Marc; et al.: Towards a standardized processing of Net Ecosystem Exchange measured with eddy covariance technique: algorithms and uncertainty estimation. Biogeosciences. 3 (4), pp. 571-583, 2006.

Petropoulos G. P. and Carlson, T. N.: Retrievals of turbulent heat fluxes and soil moisture content by remote sensing, Chapter 19, in: Advances in Environmental Remote Sensing: Sensors, Algorithms, and Applications, Ed. Taylor and Francis, 556, 667-502, 2011.

Petropoulos G., Griffiths, H. M., and Ioannou-Katidis, P.: Sensitivity exploration of SimSphere land surface model towards its use for operational products development from Earth observation data, chapter 14, in: Advancement in Remote Sensing for Environmental Applications, edited by: Mukherjee, S., Gupta, M., Srivastava, P. K., and Islam, T., Springer, 2013b.

Petropoulos, G. P., Griffiths, H. M., and Tarantola, S.: Towards Operational Products Development from Earth Observation: Exploration of SimSphere Land Surface Process Model Sensitivity using a GSA approach, 7th International Conference on Sensitivity Analysis of 25 Model Output, 1-4 July 2013, Nice, France, 2013a.

Petropoulos, G. P., Griffiths, H., and Tarantola, S.: Sensitivity analysis of the SimSphere SVAT model in the context of EO-based operational products development, Environ. Modell. Softw., 49, 166-179, 2013c.

Petropoulos, G. P., Konstas, I., and Carlson, T. N: Automation of SimSphere Land Surface Model Use as a Standalone Application and Integration with EO Data for Deriving Key Land Surface Parameters, European Geosciences Union, 7-12 April 2013, Vienna, Austria, 2013d.

Petropoulos, G., Wooster, M. J., Kennedy, K., Carlson, T.N. and Scholze, M.: A global sensitivity analysis study of the $1 \mathrm{~d}$ SimSphere SVAT model using the GEM SA software, Ecol. Model., 220, 2427-2440, 2009a.

Petropoulos, G., Carlson, T. and Wooster, M. J.: An Overview of the Use of the SimSphere Soil vegetation Atmospheric Transfer (SVAT) Model for the Study of Land Atmosphere Interactions, Sensors, 9, 4286-4308, 2009b.

Petropoulos, G.P., G. Ireland, S. Lamine, N. Ghilain, V. Anagnostopoulos, M.R. North, P.K. Srivastava \& H. Georgopoulou: Evapotranspiration Estimates from SEVIRI to Support Sustainable Water Management. Journal of Applied Earth Observation \& Geoinformation, 49, 175-187, 2016.

Petropoulos, G.P., Griffiths, H.M., Carlson, T.N., Ioannou-Katidis., P. and Holt, T.: SimSphere Model Sensitivity Analysis Towards Establishing its Use for Deriving Key Parameters 
Characterising Land Surface Interactions, Geoscientific Model Development Discussions, 7, 1873-1887, 2014.

Petropoulos, G.P., North, M. R., Ireland, G., Srivastava, P.K., \& D.V., Rendall: Quantifying the prediction accuracy of a 1-D SVAT model at a range of ecosystems in the USA and Australia: evidence towards its use as a tool to study Earth's system interactions. Geoscientific Models Development, 8, 3257-3284, 2015

Piles, M., Camps, A., Vall-Llossera, M., Corbella, I., Panciera, R., Rudiger, C., Kerr, Y. H. and Walker, J.: Downscaling SMOS-derived soil moisture using MODIS visible/infrared data, IEEE Geosci. Remote S., 49, 3156-3166, 2011.

Piles, M., G.P. Petropoulos, G. Ireland \& N. Sanchez: A Novel Method to Retrieve Soil Moisture at High Spatio-Temporal Resolution Based on the Synergy of SMOS and MSG SEVIRI observations. Rem. Sens. Environ., 2016.

Prentice, I. C., Liang, X., Medlyn, B. E., and Wang, Y. P.: Reliable, robust and realistic: the three R's of next-generation land surface modelling, Atmos. Chem. Phys., 14, 24811-24861, 2014.

Ross, S. L. and Oke, T. R.: Tests of three urban energy balance models, Bound-Lay. Meteorol., 44, 73-96, 1988.

Todhunter, P. E. and Terjung, W. H.: Intercomparison of three urban climate models, BoundLay. Meteorol., 42, 181-205, 1988.

Verbeeck, H., Samson, R., Granier, A., Montpied, P. and Lemeur, R.: Multi-year model analysis of GPP in a temperate beech forest in France, Ecol. Model., 210, 85-109, 2008.

Wilson, K., Goldstein, A., Falge, E., Aubinet, M., Baldocchi, D., Berbigier, P. and Verma, S.: Energy balance closure at FLUXNET sites, Agric. For. Meteorol., 113, 223-243, 2002. 